\title{
A randomised controlled trial of oral misoprostol vs injection methylergometrine for prevention of post partum hemorrhage
}

\author{
Neelamma B. Patil ${ }^{1 *}$, Shobhana S. Patted ${ }^{2}$
}

\begin{abstract}
${ }^{1}$ Department of Obstetrics \& Gynaecology, BLDE University’s Shri. B. M. Patil Medical College \& Research Centre, Bijapur, Karnataka, India

${ }^{2}$ Department of Obstetrics \& Gynaecology, KLE University's Javaharlal Nehru, Medical College \& Research Centre, Belgaum, Karnataka, India
\end{abstract}

Received: 2 May 2013

Accepted: 25 May 2013

*Correspondence:

Dr. Neelamma B. Patil

E-mail: patilneelgiri@rediffmail.com

(C) 2013 Patil NB et al. This is an open-access article distributed under the terms of the Creative Commons Attribution Non-Commercial License, which permits unrestricted non-commercial use, distribution, and reproduction in any medium. provided the original work is properlv cited.

\begin{abstract}
Background: To compare the efficacy of $600 \mathrm{mcg}$ of oral misoprostol with $0.2 \mathrm{mg}$ of injection methylergometrine for the prevention of post partum hemorrhage.

Methods: 200 apparently normal pregnant women were randomized to receive either $600 \mathrm{mcg}$ of oral misoprostol (study group) after delivery of baby or $0.2 \mathrm{mg}$ of methylergometrine intravenously (control group) after delivery of placenta. Primary outcome was to know the incidence of post partum hemorrhage in both the groups. Secondary outcome measures were to look for mean blood loss, need for any other uterotonic agents, need for blood transfusion, need for surgical intervention, mean duration of third stage and side effects of both the drugs.

Results: Out of 200 cases, two cases were excluded for the final analysis. Incidence of PPH was $9 \%$ in misoprostol group \& $6 \%$ in methylergometrine group which was not significant $(\mathrm{p}>0.05)$. There were no significant differences among both the groups in mean blood loss, duration of bleeding, need for further oxytocics and duration of third stage. Shivering was significantly more common in misoprostol group (36\% Vs $2 \% \mathrm{p}<0.0027)$.

Conclusion: Efficacy of $600 \mathrm{mcg}$ of oral misoprostol is comparable to injection methylergometrine $0.2 \mathrm{mg}$ intravenously for prevention of post partum hemorrhage. So, in settings where methylergometrine is used routinely for prophylaxis, oral misoprostol can be used with more ease \& other advantages over injectables. Significantly more number of patients in misoprostol will have shivering as a major side effect, which should be kept in mind.
\end{abstract}

Keywords: Postpartum hemorrhage, Misoprostol, Methylergometrine, Active management of third stage

\section{INTRODUCTION}

The World Health Organization estimates that nearly 800 women die from complications of pregnancy \& child birth every day. Among them almost $95 \%$ occur in developing countries, especially in women living in rural areas \& among poorer community. ${ }^{1}$ The Maternal mortality in developing countries is $240 / 1,00,000$ live births as compared to $16 / 1,00,000$ live births in developed countries. The commonest cause of maternal mortality is postpartum hemorrhage (PPH), which accounts for about $25-30 \%$ of maternal mortality. ${ }^{2}$ Although one or two risk factors increase the chances of
$\mathrm{PPH}$, two thirds of cases occur in women with no known risk factors. Hence all pregnant women remain 'at risk' for this catastrophic event. ${ }^{3}$

WHO recommends that all births are attended by skilled health professionals, as timely management can make the difference for life \& death. ${ }^{1}$ In India, most of the births occur at home because of the cultural preferences, economic reasons, inadequate transport systems, and limited access to skilled caregivers. ${ }^{3}$ Among them also only $46 \%$ are attended by skilled health professionals. ${ }^{1}$ So women may give birth alone or in presence of an untrained birth attendant or family members. Though 
sometimes attended by a skilled person, the birth attendant is unprepared to handle the emergency, because most often PPH is sudden and very much unexpected. ${ }^{3}$ The situation becomes still worse because of the 3 delays, namely delay in diagnosis, reference and starting the treatment.

When simpler measures like oxytocics and bimanual compression fail, other surgical procedures become necessary to control the bleeding. Most often they are available in tertiary care or referral hospitals and women must be transported for a long distance to receive these life saving services. Blood transfusions are often required and expose the women to the risk of serious transfusion reactions and infection with HIV or hepatitis B or C. Those women who survive PPH usually suffer from severe anemia and the entire experience may be emotionally devastating to the women and their families. ${ }^{3}$

Thus in countries like India with high maternal mortality and limited resources; there is a definite need for prophylaxis against $\mathrm{PPH}$.

The commonly used oxytocics are oxytocin, methylergometrine, syntometrine \& carboprost. All are given parenterally, which requires sterile needle and syringe, an important consideration in the era of hepatitis and HIV infection. ${ }^{4}$ These needles and syringes need a proper method to be disposed off. Also this requires that the birth attendant be trained and qualified to administer the drug. ${ }^{3}$ Also, these require strict storage facilities to maintain their potency which is again a major drawback in developing countries. But Misoprostol, a $\mathrm{PGE}_{1}$ analogue, has been studied widely for its usefulness in the active management of third stage of labor. It can be administered orally, sublingually, vaginally \& rectally. It does not require special storage conditions and can be stored at room temperature \& has a shelf life of several years. ${ }^{4}$ It is less inexpensive compared to other prostaglandins \& can be given safely in women with asthma and pre-eclampsia. ${ }^{5}$

So availability of such an easily administered, affordable and thermostable preparation for the routine prophylaxis for third stage of labour may have considerable benefits in the prevention of post partum hemorrhage and reduce maternal morbidity and mortality in developing countries, where atonic PPH is more common. ${ }^{6}$

Since methylergometrine is the commonly used oxytocic in our set up we decided to compare the efficacy of the orally administered misoprostol with that of intravenous methylergometrine.

\section{METHODS}

The study was conducted on women attending labour ward of district civil hospital Belgaum, Karnataka, India. The institutional ethical committee clearance was obtained for the study. The primary objective was to compare the incidence of post partum hemorrhage by oral misoprostol to that of intravenous methylergometrine. Post partum hemorrhage was taken as blood loss $\geq 500 \mathrm{ml}$ and severe $\mathrm{PPH}$ as blood loss $\geq 1000 \mathrm{ml}$. The secondary objectives were to compare mean blood loss, duration of third stage, to know the need for additional oxytocics, surgical intervention, blood transfusion in both the groups. The side effects of both the drugs were also noted.

Inclusion Criteria were gestational age equal to or greater than 28 weeks, anticipating a spontaneous vaginal delivery, ability and willingness to give informed consent. Exclusion criteria were hemoglobin level less than 7 gm\%, antepartum hemorrhage, multiple pregnancy, noncephalic presentations, pregnancy induced hypertension, previous LSCS, induced labour, instrumental delivery, cervical tear and third degree perineal tear, body temperature $>38^{\circ} \mathrm{C}$ on admission, cardiac disease, hepatic disorders \& known hypersensitivity to prostaglandins. Sample size calculations showed that with a confidence interval of $95 \%$ and power of $80 \%$, to show a difference of $20 \%$ between the efficacy of drugs, 90 cases would be required in each study group. So a sample size of 180 cases will be required. Considering the dropouts, a sample size of 200 was taken for the study. Using a computer generated randomization table, randomization of the study subjects was done. The codes given were ' $T$ ' for those patients who will receive misoprostol tablets and 'I' for those who will receive injection methylergometrine.

When eligible women presented to labour ward, they were screened for the enrollment in the study using the inclusion and exclusion criteria. Informed consent was taken for those who fulfilled the criteria. Once the patient delivered vaginally without any instrumentation she was randomized according to the randomization table. If patient develops any of the conditions mentioned in exclusion criteria after randomization she was excluded from analysis. If she belonged to ' $\mathrm{T}$ ' group she will receive 3 tablets of misoprostol $(600 \mathrm{mcg})$ orally after the baby is delivered within one minute. If she belonged ' $\mathrm{I}$ ' group, she will receive injection methylergometrine $1 \mathrm{ml}(0.2 \mathrm{mg})$ by intravenous route immediately after the delivery of placenta. Since the study was conducted in government hospital set up with lot of work load, methylergometrine was routinely given after the expulsion of placenta to reduce the chances of retained placenta.

If oxytocin was started for augmentation, it was stopped at the end of $2^{\text {nd }}$ stage. All the episiotomies were mediolateral. The table was cleaned of liquor and a clean metal tray was kept over the waste collection box kept at the edge of the delivery table to collect the blood. This was found to be a comfortable and efficient way of collecting blood after delivery. It could be left in place without discomfort even during perineal suturing.

If active bleeding did not stop irrespective of the allocation of medication, $20 \mathrm{U}$ of oxytocin in $500 \mathrm{ml}$ saline 
was used. If still not controlled then injection carboprost $\left(\mathrm{PGF}_{2 \alpha}\right) 250 \mathrm{mcg}$ was given intramuscularly. If it does not get controlled with this patient was managed according to the duty doctor's advice. Because these interventions might obscure difference in blood loss between the groups, the need for additional oxytocics was chosen as a secondary outcome.

The patient was observed in the labor ward for one hour for any excessive bleeding and side effects of drugs like nausea, vomiting, headache, shivering, pyrexia $\left(\geq 100^{\circ} \mathrm{F}\right.$, checked only if indicated) and diarrhea. If the side effects were found to be severe appropriate treatment was given.

Once the active bleeding stopped, collected blood was weighed. As weight of blood at the end of one hour or two hours after collection is equal to the volume of blood measured in millilitres ${ }^{7}$, weight of blood in grams was directly taken as blood loss in millilitres. Blood transfusion was given whenever the blood loss was more than $1000 \mathrm{ml}$ or clinically indicated. Records of pulse rate and blood pressure before delivery and at the end of one hour after delivery were kept.
The process of enrollment, informed consent, randomization, estimation of blood loss and completion of proforma was evaluated frequently by the principal investigator of the study to maintain the quality of study.

\section{RESULTS}

A total of 200 women, who fulfilled the eligibility criteria, were studied. Out of these 200 cases, one case from each group was excluded. A case of third degree perineal tear in methylergometrine group and a case of adherent placenta in misoprostol group were excluded. Total of 198 cases were analyzed.

$\mathrm{Z}$ test was used to compare the means. $\mathrm{Z}$ value of $>1.96$ was considered significant. Whenever the number of cases was less than $30, \mathrm{t}$ test was used. $\mathrm{P}$ value was derived directly using value of $t$ table. $\mathrm{P}$ value $<0.05$ was taken as significant.

There were no statistically significant differences between the groups for baseline variables as shown in Table 1 .

Table1: Baseline variables.

\begin{tabular}{|lllll|}
\hline Variables & Misoprostol & Methylergometrine & Z value & P value \\
\hline Age & 23.29 & 23.59 & 0.60 & NS \\
\hline Gravida & 2.07 & 2.04 & 0.22 & NS \\
\hline Parity & 1.01 & 0.96 & 0.40 & NS \\
\hline Gest. Age & 38.72 & 39.19 & 1.40 & NS \\
\hline High risk & 25 & 36 & 1.69 & NS \\
\hline Anemia & 10 & 17 & 1.45 & NS \\
\hline Registered & 58 & 68 & 1.48 & NS \\
\hline Unregistered & 42 & 32 & 1.47 & NS \\
\hline Pulse rate & 82.86 & 82.06 & 0.77 & NS \\
\hline SBP & 120.30 & 120.40 & 0.08 & NS \\
\hline DBP & 75.28 & 75.90 & 0.74 & NS \\
\hline Episiotomy & 30 & 34 & 0.60 & NS \\
\hline Perineal tear & & & & \\
\hline I & 6 & 5 & 0.31 & NS \\
\hline II & 1 & 1 & 0.0 & NS \\
\hline III & 0 & 7.83 & 1.00 & NS \\
\hline Duration of labour & & 23.18 & 0.15 & NS \\
\hline $1^{\text {st }}$ Stage & 7.91 & & & NS \\
\hline $2^{\text {nd }}$ Stage & 22.98 & 1 & 0.15 & \\
\hline
\end{tabular}


Nine out of 99 cases in misoprostol group and 6 out of 99 cases in methylergometrine group had the measured blood loss of more than $500 \mathrm{ml}$ (Table 2). This difference was not statistically significant $(\mathrm{z}=0.18$ and $\mathrm{p} \geq 0.05)$. There were no cases of severe postpartum hemorrhage i.e. measured blood loss of $1000 \mathrm{ml}$ or more, in both the groups. Though there was a trend towards more blood loss in misoprostol group, but this was not statistically significant. There were 69 cases of blood loss less than $250 \mathrm{ml}$ in misoprostol group and 81 cases in methylergometrine group. This finding was statistically significant with a $\mathrm{p}$ value of $<0.05$ and $\mathrm{z}$ value of 1.99 . But mean blood loss was not significant.

Mean duration of third stage was also not statistically significant between both the groups (Table 2). Only one case in misoprostol group had prolonged third stage (more than 30 minutes) and required manual removal of placenta because of adherent placenta. This case was excluded from the analysis.

Four patients in the misoprostol group and one in the methylergometrine group required oxytocin as an additional oxytocic (Table 2). This was not statistically significant. Two patients in misoprostol group and one in methylergometrine group required both oxytocin and carboprost. So, total of six patients in misoprostol group and two patients in methylergometrine group required further oxytocics, which was not statistically significant.

When blood loss in the subgroups was calculated (Table 3 ), it was seen that misoprostol was not as effective as methylergometrine in primigravida ( $208 \mathrm{ml}$ vs $142 \mathrm{ml}, \mathrm{p}$ value $<0.05$ ), but was equally effective in multigravida. Blood loss was also significantly more in misoprostol group who had episiotomy. This may be because; episiotomy is routinely given for all primigravidae in our set up. In other subgroups as shown in Table 3, it was as effective as methylergometrine.

Duration of bleeding was assessed by taking intervals of less than 30 minutes, 30 to 60 minutes and for more than 60 minutes. In 95 cases of misoprostol group and 98 of methylergometrine group, bleeding stopped within 30 minutes (Table 4). Four cases in misoprostol group and one case in methylergometrine group had bleeding for more than 30 minutes, but for less than 60 minutes. Both these differences were not statistically significant. None of them had bleeding for more than one hour.

Only one patient in misoprostol group, who was a case of adherent placenta with a blood loss of $1000 \mathrm{ml}$, required blood transfusion \& surgical intervention (Manual removal of placenta), but was excluded from the final analysis. None of the cases in methylergometrine group required blood transfusion or surgical intervention. Decision for blood transfusion was taken based on clinical features of excessive blood loss.

Nausea was more common in methylergometrine group, compared to misoprostol group, but this was not statistically significant. ( $\mathrm{p} \geq 0.05$ and $\mathrm{z}=1.19$ ). Vomiting occurred in equal numbers of patients in both the groups. Shivering was significantly more common in misoprostol group compared to methylergometrine group. (36 Vs $2, \mathrm{p} \leq$ 0.027 and $\mathrm{z}=6.14$ ). Fever (body temperature of $>38^{\circ} \mathrm{C}$ ) occurred in two patients of misoprostol group and none in methylergometrine group. This was not statistically significant. There were no cases of headache and diarrhea noted in both the groups. There were no new side effects noted for both the drugs (Table 5).

Table 2: Outcome measures.

\begin{tabular}{|lllll|}
\hline Outcome & Misoprostol & Methylergometrine & Z Value & P Value \\
\hline PPH & 9 & 6 & 0.81 & $>0.05$ \\
\hline Mean blood loss & $211 \pm 172 \mathrm{ml}$ & $178 \pm 137 \mathrm{ml}$ & 1.48 & $>0.05$ \\
\hline Duration of $3^{\text {rd }}$ stage & $7.79 \mathrm{~min}$ & $7.86 \mathrm{~min}$ & 0.17 & $>0.05$ \\
\hline Need for further oxytocics & $6 \%$ & $2 \%$ & 1.14 & $>0.05$ \\
\hline
\end{tabular}

Table 3: Blood loss in subgroups.

\begin{tabular}{|llll|l|}
\hline Subgroup & Misoprostol & Methylergometrine & Z Value & P Value \\
\hline Primigravida & $208 \pm 144 \mathrm{ml}(31) \dagger$ & $142 \pm 82 \mathrm{ml}(34)$ & 2.18 & $<0.05$ \\
\hline Multigravida & $200 \pm 158 \mathrm{ml}(68)$ & $195 \pm 157 \mathrm{ml}(65)$ & 0.23 & $>0.05$ \\
\hline Anaemia & $172 \pm 104 \mathrm{ml}(10)$ & $131 \pm 99 \mathrm{ml}(17)$ & 0.96 & $>0.05$ \\
\hline Prolonged labour & $170 \pm 113 \mathrm{ml}(16)$ & $135 \pm 108 \mathrm{ml}(16)$ & 0.87 & $>0.05$ \\
\hline Episiotomy & $208 \pm 146 \mathrm{ml}(33)$ & $142 \pm 82 \mathrm{ml}(34)$ & 2.18 & $<0.05$ \\
\hline Perineal tear & $314 \pm 194 \mathrm{ml}(6)$ & $201 \pm 130 \mathrm{ml}(7)$ & 1.11 & $>0.05$ \\
\hline
\end{tabular}

$\dagger$ Indicates total number of cases in subgroups 
Table 4: Duration of bleeding.

\begin{tabular}{|l|llll|}
\hline Duration(min) & Misoprostol & Methylergometrine & $Z$ value & $P$ value \\
\hline$<30$ & 95 & 98 & 1.35 & NS \\
\hline $30-60$ & 4 & 1 & 1.25 & NS \\
\hline $60-120$ & - & - & - & - \\
\hline$>120$ & - & - & - & - \\
\hline
\end{tabular}

Table 5: Side effects.

\begin{tabular}{|lllll|}
\hline Side Effects & Misoprostol & Methylergometrine & $\boldsymbol{t}$ value & $\boldsymbol{P}$ value \\
\hline Nausea & $4(2) \ddagger$ & $8(1)$ & 1.19 & NS \\
\hline Vomiting & $3(3)$ & $3(3)$ & - & - \\
\hline Diarrhoea & - & - & - & - \\
\hline Shivering & $36(18)$ & $2(1)$ & 6.14 & $<0.0027$ \\
\hline Fever & $2(2)$ & 0 & 1.42 & NS \\
\hline Head ache & - & - & - & - \\
\hline Others & - & - & - & - \\
\hline
\end{tabular}

$\ddagger$ Numbers in the bracket indicate total number cases requiring treatment

\section{DISCUSSION}

The FIGO-ICM definition of active management of third stage of labor (AMTSL) includes, use of a uterotonic immediately following delivery of the fetus, controlled cord traction and fundal massage immediately after delivery of the placenta, followed by palpation of the uterus every 15 minutes for 2 hours to assess the continued need for massage. 8 Cord clamping is excluded based on research indicating that delayed clamping benefits the infants. Although there has been little research into the effects of the individual components of active management of the third stage of labor, ${ }^{8}$ when all the components are practiced for the third stage management, it definitely reduces the incidence of PPH.

Although active management of the third stage of labour is effective and has been widely promoted, data on the use of the practice are limited. One report on its use in 15 university teaching hospitals in 10 countries showed the rates of use ranging from $0 \%$ to $98 \%$, with no pattern of difference between developing and developed countries. ${ }^{8}$ In five countries, less than $5 \%$ of deliveries met the criteria for the FIGO-ICM definition, which is the most stringent. Relaxing the time of administration of the uterotonic to within 3 minutes after fetal delivery increased the use of active management of the third stage of labor. ${ }^{8}$
In a busy government hospital set up it becomes difficult to strictly follow all the components of AMTSL, especially timing of the uterotonic agent. If timing is not correct it can cause either entrapment of fetus or placenta especially with methylergometrine. Because of these concerns only, methylergometrine was routinely given after delivery of placenta in our set up. This is one of the drawbacks of the injectable uterotonics, which require a skilled person for its administration. But oral misoprostol can be administered even by the patient's relatives or any other unskilled person \& timing of administration can be maintained. Since in our study we wanted to compare the effect of misoprostol with the currently practiced method of active management in our set up, methylergometrine was given after delivery of placenta.

Prostaglandins are effective myometrial stimulants and have been used to treat established postpartum hemorrhage for years. Because of the concerns of safety, cost and adverse effects of prostaglandins, they were not considered for prophylactic treatment, until the uterotonic property of misoprostol was recognized. Misoprostol is inexpensive, easy to store, and systemically absorbed orally and across mucous membranes, thus it was projected to be a promising substitute for other established injectable agents. ${ }^{9}$ Though a WHO review in $2009^{10}$ concluded that sublingual is the most promising route, there are chances of patient spitting it out if she does not like the taste. Oral route is faster than vaginal \& 
rectal route, being detected in the circulation within $2 \mathrm{~min}$ of its oral ingestion. ${ }^{9}$ It is primarily metabolized in liver, so dose has to be adjusted in hepatic disorders, but not required in renal disorders. It does not induce hepatic enzyme system and has no drug interactions. Maximum dose tolerated is up to $2200 \mu \mathrm{g}$ over a period of 12 hours. The most common adverse effects are nausea, vomiting, diarrhea, abdominal pain (cramps), shivering and fever. It does not cause bronchospasm and hypertension. ${ }^{5}$ Its usefulness in the active management of third stage of labor was first shown by Hazem El-Rafaey from United Kingdom. ${ }^{11}$

Methylergometrine is not stable at high temperatures and needs to be stored between $2-8^{\circ} \mathrm{C}$ and must be protected from light. Studies done in tropical countries have shown that variety of brands of ergometrine lose $21-27 \%$ of their potency after one month and over $90 \%$ after one year of storage exposed to light and at $21^{\circ} \mathrm{C} .{ }^{12}$ These storage requirements are important hurdle for its use in developing countries.

There are only few studies done so far, comparing inj. Methylergometrine $0.2 \mathrm{mg}$ intravenously with misoprostol $600 \mathrm{mcg}$ given orally for the control of postpartum hemorrhage.

Fredric Amant et $\mathrm{al}^{13}$ conducted a randomized controlled trail on 200 women to compare the efficacy of misoprostol and methylergometrine given after the delivery of the baby. Blood loss was clinically estimated. Our study results are comparable to that study, where the incidence of PPH was $8.3 \%$ in misoprostol group \& $4.3 \%$ in methylergometrine group which was not statistically significant. Need for additional oxytocics, duration of third stage, need for blood transfusion \& surgical intervention were also comparable between the groups.

The large randomized multi centre hospital based study, conducted by World Health Organization ${ }^{14}$ on 18,459 patients showed that $10 \mathrm{IU}$ oxytocin given parenterally (intravenous or intramuscular) was significantly better than $600 \mathrm{mcg}$ of oral misoprostol in the prevention of blood loss $\geq 500 \mathrm{ml}$ and $\geq 1000 \mathrm{ml}$. But there were fewer blood transfusions in misoprostol group, suggesting that the effect of misoprostol on greater volumes of blood loss may have been greater. ${ }^{15}$ Gambian study ${ }^{15}$ also showed that effect of misoprostol is more apparent for serious postpartum hemorrhage (blood loss $\geq 750 \mathrm{ml}$ or $\leq$ $1000 \mathrm{ml}$ ), but their study was not powered to estimate this outcome. The present study also showed that, for the blood loss of more than $250 \mathrm{ml}$, misoprostol was as effective as methylergometrine. Meta analysis of randomized controlled trials will be required to provide a more precise assessment of the effectiveness of misoprostol on severe postpartum hemorrhage. ${ }^{15}$

Previous studies done with misoprostol and placebo had shown that $600 \mathrm{mcg}$ of oral misoprostol was significantly more efficacious than placebo in controlling third stage blood loss. ${ }^{16}$ Similar results were also shown by a prospective observational study by Hazem El Refaey. ${ }^{12}$ A placebo-controlled study done with $400 \mathrm{mcg}$ of misoprostol, showed that it was not better than a placebo. ${ }^{17}$ Increasing the dose to get more efficacy can lead to higher incidence of side effects. Pisake et $\mathrm{al}^{18}$ conducted a randomized, double blind pilot study to select the dose of misoprostol, to be used in a large randomized controlled trial comparing misoprostol with oxytocin. Both shivering and pyrexia were more common with $600 \mathrm{mcg}$ of misoprostol as compared to $400 \mathrm{mcg}$. But shivering was primarily due to higher rate of moderate shivering. None of the women had temperature more than $40^{\circ} \mathrm{C}$. There was no increase in severe side effects and other adverse events with $600 \mathrm{mcg}$ of misoprostol. The mean blood loss was comparable between $400 \mathrm{mcg}$ and $600 \mathrm{mcg}(371 \mathrm{ml} \mathrm{Vs} 341 \mathrm{ml})$. Doses reaching up to $800 \mathrm{mcg}$ have been used for abortion purpose without major side effects. Shivering is a recognized symptom after normal delivery and is more common with epidural anesthesia, occurring in $33 \%$ to $60 \%$ of deliveries. This incidence after normal delivery, without epidural anesthesia is about $10 \%$, which might be increased by misoprostol. ${ }^{17}$ Considering the observed rates of side effects in WHO trial, the authors advised that doses greater than $600 \mathrm{mcg}$ orally should not be tested for prevention of postpartum hemorrhage. ${ }^{14}$ Based on these studies, which showed that $600 \mathrm{mcg}$ of oral misoprostol is efficacious with good safety profile, we decided to use $600 \mathrm{mcg}$ of oral misoprostol.

Various studies have shown that, visual estimation underestimates the blood loss by half. ${ }^{19}$ The blood loss was measured objectively in the present study. Great efforts were taken to measure the blood loss carefully, but the measurement remains open to inaccuracies due to inclusion of some amniotic fluid and omission of some blood that can spatter on drapes and gowns. This can especially affect the measurement of lower amounts of blood loss. However, the likely measurement error should be random and will therefore reduce the power, but not bias the results. The collection method, which we had used, was found to be a comfortable and efficient way of collecting a great majority of the blood loss following delivery. It could also be left in place without discomfort even during perineal suturing.

Critics of the WHO trial say that, there is no need for misoprostol to replace oxytocin or ergometrine for prophylaxis of postpartum hemorrhage in city hospitals around the world where the trial was conducted. Instead, it needs to be available to the midwives for deliveries in the homes of women and to doctors in rural areas to treat women who may bleed to death because parenteral drugs are not practical to administer or not available. ${ }^{20}$ In these situations, tablets have clear advantage over injectables even if they are a third less effective than the injections, as the WHO group found. ${ }^{7}$ Ensuring the availability of misoprostol where oxytocin is not available or where temperature requirements for oxytocin storage are 
difficult to meet could help prevent postpartum hemorrhage. ${ }^{10}$ But care should be taken in training the health care provider regarding the proper use of misoprostol, so that possible harm effects like, its use before delivery which can lead to uterine rupture and over dosing are avoided. ${ }^{15}$

\section{Limitations of the study}

1) Double blinding of the study would have minimized the observer bias in our study, but this was not possible due to difficulty in getting the placebo.

2) Since in our study we wanted to compare the effect of misoprostol with the currently practiced method of active management in our set up, methylergometrine was given after delivery of placenta.

3) Swabs and pads used during $3^{\text {rd }}$ stage were not counted for blood loss, but were kept to minimum of $<3$.

4) Side effects were observed for only one hour. The diarrhea usually occurs after one hour with misoprostol, so the incidence of diarrhea could not be calculated.

\section{CONCLUSION}

Efficacy of $600 \mathrm{mcg}$ of oral misoprostol is comparable to injection methylergometrine $0.2 \mathrm{mg}$ intravenously for prevention of post partum hemorrhage. So, in settings where methylergometrine is used routinely for prophylaxis, oral misoprostol can be used with more ease \& other advantages over injectables. Significantly more number of patients in misoprostol will have shivering as a major side effect, which should be kept in mind.

\section{Funding: None}

Conflict of interest: None

Ethical approval: Approved by the institutional ethical committee

\section{REFERENCES}

1. Maternal mortality- Media centre" Fact sheet N³48;May 2012, http://www.who.int/mediacentre/ factsheets/fs348/en/index.html.

2. Park K. Preventive and Social Medicine. $21^{\text {st }}$ ed. Chapter no.9. Jabalpur: M/S. Banarsidas Bhanot Publishers; 2005:383-437.

3. McCormick M.L., Sanghvi H.C.G., Kinize B., McIntosh N. Preventing post partum hemorrhage in low resource settings. International journal of Gynecology and Obstetrics India 2002; 7(5):52-60.

4. Hazem E R, Nooh Randa, Pat O' Brien, Mona Abdalla, Michael G., Jane Wadler, Charles R. The misoprostol third stage of labour study: a randomized controlled comparison between orally administered misoprostol and standard management. BJOG September 2000; 107:1104-1110.

5. Godman, Gilman. The pharmacological basis of therapeutics. $10^{\text {th }}$ ed, Chapter No.37. USA : McGraw-Hill; 2001 : 1005-1020.

6. Caliskan Eray, Meydanli Mutlu M. Dilbaz Berna, Ayakan Burcu, Sonmezer Meral, HAberal Ali. Is rectal misoprostol really effective in the treatment of third stage of labor? A randomized controlled trial. Am J Obstet Gynecol 2002;187: 1038-45.

7. James D.K. Steer P.J. Weiner C.P. Gonik B. High risk pregnancy management options. $2^{\text {nd }}$ ed. Chapter 69. W.B. Sounders 2003; 1231-1246.

8. Cynthia Stanton, Deborah Armbruster, Rod Knight, Iwan Ariawan, Sourou Gbangbade, Ashebir Getachew et al. Use of active management of the third stage of labour in seven developing countries. Bulletin of the World Health Organization 2009;87:207-215.

9. Aman Bhullar, Carlan SJ, Hamm Jennifer, Lambety Norman, White Leigh, Richichi Kris. Buccal misoprostol to decrease blood loss after vaginal delivery: A randomized trail. Obstet Gynaecol 2004;104(6): 1282-1288.

10. G Justus Hofmeyr, A Metin Gülmezoglu, Natalia Novikova, Verena Linder, Sandra Ferreira, Gilda Piaggio. Misoprostol to prevent and treat postpartum hemorrhage: a systematic review and meta-analysis of maternal deaths and dose-related effects. Bulletin of the World Health Organization 2009; 87:666-677.

11. Hazem El-Rafaey, Pat O’ Brien, Wale Morafa, Jane Walder, Charles Rodeck. Misoprostol for third of stage of labor. Lancet 1996:347:1257.

12. Hazem El- Refaey, Pat O'Brien, Wale Morafa, Jane Walder, Charles Rodeck. Use of oral misoprostol in the prevention of postpartum haemorrage. British Journal of Obstetrics \& Gynaecol 1997; 104: 336339.

13. Amant Frederic, Spitz Bernard, Timmerman Dirk, Corremans Annick, Assche Van Andre frans. Misoprostol compared with methylergometrine for the prevention of postpartum hemorrhage: a doubleblind randomized trial. British Journal of Obstet \& Gynecol 1999; 106: 1066-1070.

14. Gulmezoglu AM, Villar J. Ngoc, Piaggio G, Carroli $\mathrm{G}$, Adetoro L, Abdel-Aleem $\mathrm{H}$ et al. WHO multicenter randomized trial of misoprostol in the management of third stage of labor. Lancet 2001; 358:689-695.

15. Walraven G, Blum J, Dampha Y, Sowe M, Morison L. et al. Misoprostol in the management of third stage of labor in home delivery setting in rural Gambia: a randomized controlled trial. Br J Obstet \& Gynaecol 2005;112:1-7.

16. Surbek Daniel V., Fehr Peter M., Hosle Irene., Holzgreve Wolfgang. Oral misoprostol for the third stage of labor: A randomized placebo-controlled trial. Obstet \& Gynecol 1999; 94:255-258. 
17. Walley Robert L, Wilson John B, Crane JMG, Mathews Kay, Sawyer Elizabeth, Hutcheas Donna. A double-blind placebo controlled randomized trial of misoprostol and oxytocin in the management of third stage of labor. British Journal of Obstet \& Gynecol 2000;107:1111-1115.

18. Lumbiganon Pisake, Hofmeyr J, Gulmezoglu AM, Pinol A, Villra J. Misoprostol dose-related shivering and pyrexia in the third stage of labor. British Journal of Obstet \& Gynecol 1999;106:304-308.

19. Gary C F, Kenneth J.L, Steven L.B, John C.H, Larry C., Kathetrine D.W. Williams Obstetrics. $23^{\text {nd }}$ ed. Chapter no. 35. USA: Macgraw Hill publication; 2005:809-854.

20. Darney PD. Misoprostol: a boon to safe motherhood... or not? Lancet 2001;358:682-683.

DOI: $10.5455 / 2320-1770 . i j r \operatorname{cog} 20130908$

Cite this article as: Patil NB, Patted SS. A randomised controlled trial of oral misoprostol vs injection methylergometrine for prevention of post partum hemorrhage. Int J Reprod Contracept Obstet Gynecol 2013;2:296-303. 